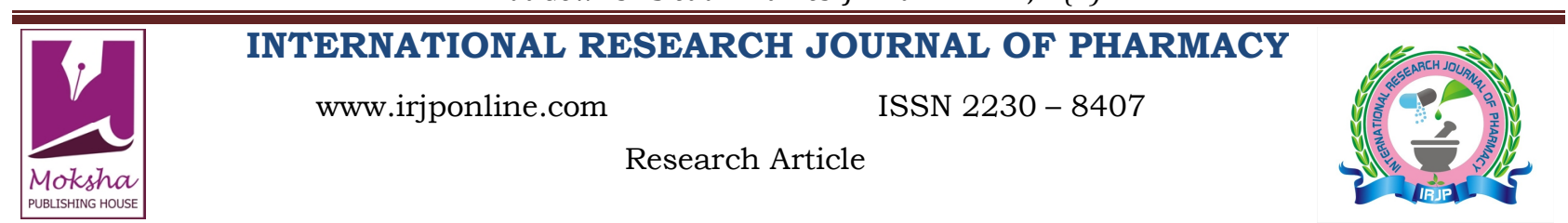

\title{
A COMPARATIVE EVALUATION OF EFFECT OF SODIUM HYPOCHLORITE ON MICROTENSILE BOND STRENGTH OF THREE DIFFERENT BONDING AGENTS TO THE LATERAL WALLS OF PULP CHAMBER: AN IN VITRO STUDY
}

\author{
Bhat Gowrish S. ${ }^{1 *}$, Mohan B. ${ }^{2}$, Lakshminarayanan.L. ${ }^{3}$, Savadamoorthi ${ }^{3}$ \\ ${ }^{1}$ Department of Conservative Dentistry and Endodontics, A.B.Shetty Memorial Institute of Dental Sciences, Nitte University \\ Derlakatte, Mangalore, Karnataka, India \\ ${ }^{2}$ Department of Conservative Dentistry and Endodontics, S.R.M. Dental college, Kottankolathur, Chennai, India \\ ${ }^{3}$ Department of Conservative Dentistry and Endodontics, Thai mookakbikai dental college, Golden George nagar, Chennai, \\ India \\ E mail:gsbhat@sify.com
}

Article Received on: 12/01/13 Revised on: 03/02/13 Approved for publication: 13/03/13

DOI: $10.7897 / 2230-8407.04331$

IRJP is an official publication of Moksha Publishing House. Website: www.mokshaph.com

(C) All rights reserved.

\begin{abstract}
The advent of adhesive materials has revolutionized the field of restorative dentistry. Lack of adhesion and sealing between the final restoration and tooth structure may lead to microleakage and ultimate failure of the restoration. These adhesive restorations are also being used in the field of endodontics. A good coronal seal is very important, since the penetration of microorganisms from a coronal direction can reinfect the root canal system and affect the prognosis of the non-surgical root canal therapy. Coronal leakage is particularly significant in multi rooted teeth, in which accessory canal may allow inflammatory change to occur in the periodontal tissues from the pulp chambers. Improper restoration can lead to loss of endodontically treated teeth more than actual failure of endodontic therapy. The restorations with adhesive systems offer the advantage of transmission of functional stresses across the bonded interface to the tooth (mono bloc restoration) and potentially reinforce the weakened tooth structure. Bonding to pulp chamber lateral walls is different from bonding other dentinal surface. The structure of pulp chamber wall is complicated and not much is known about the bonding characteristics of pulp chamber, it becomes essential to study the same. This study was done evaluate the effect of sodium hypochlorite on bond strength of bonding agent to the lateral walls of the pulp chamber. However, chemical irrigants, such as sodium hypochlorite used in the endodontic treatment have been shown to affect the bond strength of resin composite to dentin adversely.

Key Words: microtensile bond strength, pulp chamber, microleakage, bonding agents, sodium hypochlorite
\end{abstract}

\section{INTRODUCTION}

There are various methods available to evaluate the bond strength to enamel and / or dentin, mainly by subjecting composite bonded substrate to tensile or shear stress. A microtensile bond strength methodology has shown that the bond strength is inversely related to the bonded surface area. It eliminates the flaws or defects at the interface of the specimen owing to the small size of the specimen and enables evaluation of regional bond strength and bonding effectiveness to clinically relevant tooth substrate. The aim of this present study was to evaluate the effect of Sodium hypochlorite on micro tensile bond strength of three different bonding agents to the lateral walls of the pulp chamber.

\section{MATERIALS AND METHODS}

Thirty freshly extracted non carious human mandibular third molar teeth with fully developed apices stored in saline were taken up for the study. The superficial portion of the pulp chambers were removed by using a slow speed diamond disk under running water. To avoid touching pulpal wall dentin, the pulp tissue was then removed carefully with a spoon excavator. The teeth were randomly divided into two groups of 15 each. In Group I, the pulp chambers of teeth were irrigated with 3\% sodium hypochlorite solution for 1 minute and rinsed with distilled water for 1 minute. The specimens in group II were irrigated with distilled water.

These specimen were further divided into group of five teeth each based on the bonding agents used, which consisted of SubgroupA-Singlebond2, subgroup B -Prime and Bond NT, sub group $\mathrm{C}-\mathrm{AdheSE}$. The adhesive systems were applied to the walls of the pulp chambers of the teeth according to the manufacturer's instructions. After light curing the bonding agent, posterior composite (Solitaire) was condensed into the pulp chamber and cured in increments of $2 \mathrm{~mm}$ layers on the bonded surface. Astralis 3 light curing unit with a light intensity of $400 \mathrm{~mW} / \mathrm{cm}^{2}$ was used in this study. The restored teeth were stored in distilled water at $37 \%$ c for 24 hours until the evaluation.

The teeth were then embedded in acrylic resin (auto polymerizing acrylic resin). This was followed by sectioning in a slow speed hard tissue microtome (Leika, Germany) under running water. 2-3 discs of $1 \pm 0.02 \mathrm{~mm}$ thickness were obtained from each tooth. The sections were prepared to obtain rectangular sticks of $1 \pm 0.02 \mathrm{~mm}^{2}$ dimensions, which were measured using a digital caliper. Total of 60 slabs were obtained with 20 slabs per each sub group.

A custom made jig was fabricated for the purpose of testing the micro tensile bond strength ( $\mu \mathrm{TBS}$ ) from OHS (oil hardened steel) with a dimension of $8 \mathrm{~mm} \times 10 \mathrm{~mm} \times 60 \mathrm{~mm}$. A slot of $1 \mathrm{~mm} \times 2 \mathrm{~mm}$ dimension was made on each half of the jig to attach the specimen. The rectangular specimen were attached to the jig with cyanoacrylate adhesive been applied to the composite and dentin side of the specimen. After setting the jig was attached to the testing apparatus (universal testing machine) and subjected to tensile forces at a cross head speed of $1 \mathrm{~mm}$ per minute. The microtensile bond strength values were determined in $\mathrm{MPa}$ (Mega Pascal).

Statistical analysis was done with Student's independent ttest for calculating the P-value between group I and group II and between the subgroup A, subgroup B and subgroup C. One- way Anova was used to calculate the P-value among the subgroups in group I and II. Multiple Range Test by TukeyHSD procedure was employed to identify the significant groups at $5 \%$ level. 
Bhat Gowrish S et al. Int. Res. J. Pharm. 2013, 4 (3)

Table 1: Mean and standard deviation (S.D)

\begin{tabular}{|c|c|c|c|c|c|c|}
\hline \multicolumn{4}{|c|}{ Group I } & \multicolumn{3}{|c|}{ Group II } \\
\hline & Subgroup A & Subgroup B & Subgroup C & Subgroup A & Subgroup B & Subgroup C \\
\hline Mean & 22.5 & 15.7 & 18.6 & 28.2 & 17.2 & 21.5 \\
\hline S.D & 1.6 & 0.9 & 0.5 & 0.9 & 1.0 & 1.0 \\
\hline
\end{tabular}

Table 2: Mean, standard deviation and test of significance of mean values between group 1 and 2

\begin{tabular}{|c|c|c|c|}
\hline Group & n & Mean \pm S.D & P-Value \\
\hline I & 30 & $19.0 \pm 3.0$ & 0.002 \\
\hline II & 30 & $22.3 \pm 4.7$ & \\
\hline
\end{tabular}

Table 3

\begin{tabular}{|c|c|c|c|c|}
\hline Group & Subgroup & Mean \pm S.D & P-Value & Significant groups at 5\% level \\
\hline & A & $22.5 \pm 1.6$ & & A Vs B, C \\
\hline I & B & $15.7 \pm 0.9$ & $<0.0001$ & C Vs B \\
\hline & C & $18.6 \pm 0.5$ & & A Vs B, C \\
\hline II & A & $28.2 \pm 0.9$ & & C Vs B \\
\hline
\end{tabular}

Table 4: Comparison of mean values between group I and II for different subgroups

\begin{tabular}{|c|c|c|c|}
\hline Subgroup & Group I & Group II & P- Value \\
\hline A & $22.5 \pm 1.6$ & $28.2 \pm 0.9$ & $<0.0001$ \\
\hline B & $15.7 \pm 0.9$ & $17.2 \pm 1.0$ & 0.003 \\
\hline C & $18.6 \pm 0.5$ & $21.5 \pm 1.0$ & $<0.0001$ \\
\hline
\end{tabular}

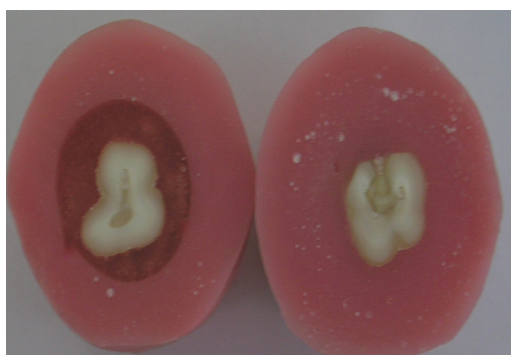

Figure 1: Sectioned specimen
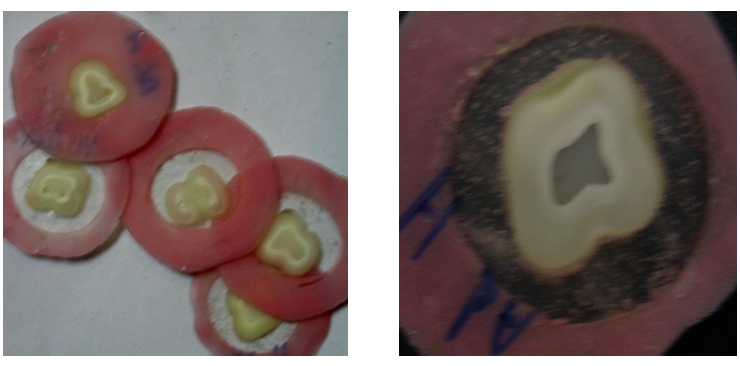

Figure 2: Cut specimen
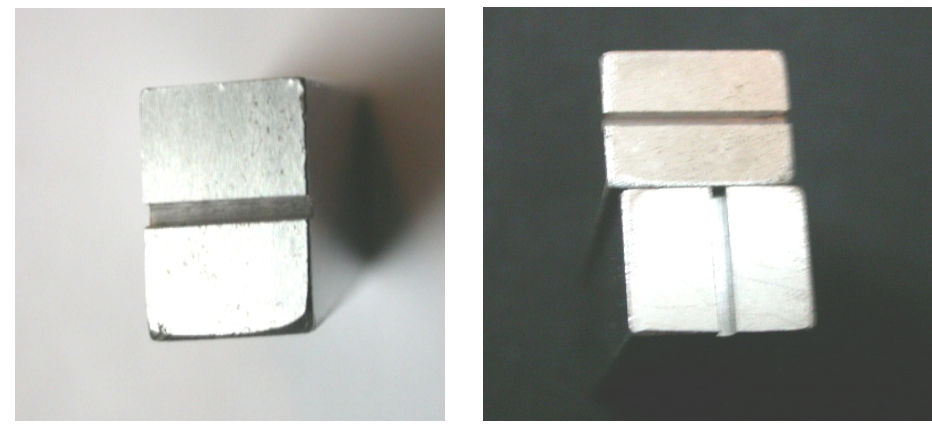

Figure 3: Custom made jig

\section{RESULTS}

The microtensile bond strength values were obtained and the mean and standard deviation (S.D) are given in Table 1. The graphical representation is given in Figure 1.The statistical analysis are given in Table 2,3 and 4.From the results it can be inferred that the highest bond strength was found in Group II (with out sodium hypochlorite irrigation) when compared to Group I in which sodium hypochlorite was used. When comparing with in the groups, Single Bond 2 showed better results followed by AdheSE followed by Prime \& Bond NT.

\section{DISCUSSION}

Achievement of the bond between resin and dentin depends on the penetration of the primer and the adhesive resin into the conditioned dentin surface in order to create micromechanical interlocking between the dentin collagen and resin to form a hybrid layer ${ }^{1}$.

Sodium hypochlorite is one of the most commonly used chemical irrigants in endodontic treatment procedure. It is used in concentration of $2.6 \%$ to $5.2 \%, 3 \%$ concentration being used most popularly for endodontic purposes. Sodium hypochlorite application results in gross debridement, lubrication, collagen and tissue dissolution, deproteinization, microbial destruction, removal of collagen layer, collagen alteration and dehydration of dentin ${ }^{2}$. The lubricant action is due to the formation of soap $\mathrm{Na}(\mathrm{OH})_{2}$ in the initial stages of sodium hypochlorite dissolution The deproteinizing and 
antibacterial effects and tissue dissolution and collagenolytic actions are mainly attributed to the free chlorine available.

The chlorine released from dissociation of sodium hypochlorite combines with the proteins and results in breakdown of proteins into amino acids by chloramine reaction. By this it removes the predentin by dissolution of collagen there by enlarging the tubule orifices. Sodium hypochlorite has shown to change the calcium and phosphate ratio of dentin surface and alters the chemical structure ${ }^{3-}$ ${ }^{5}$. The alteration in $\mathrm{Ca} / \mathrm{P}$ ratio may change the original ratio between organic and inorganic components that in turn change the permeability and solubility characteristics of dentin and also affect the adhesion of dental materials to hard tissue, especially the bond strength of resin composite to dentin adversely ${ }^{5-7,8}$.

Numerous commercial bonding systems are available for good hybridization and adequate bonding. Based on the adhesion strategy they can be classified as "etch and rinse", self-etch" and glass ionomer ("resin modified") adhesives.

The subgroup A and subgroup B represented the 'etch and rinse' adhesives and subgroup $\mathrm{C}$ represented 'intermediate' self- etch adhesive in this study.

"Non- trimming" version technique was used to prepare the specimen, since the other techniques of evaluating $\mu$ TBS either with T-shaped or hour glass shaped specimen have shown to undergo failure at lower forces due to stress created while specimen preparation. On the other hand specimen preparation by restricting the bonding area to $1 \mathrm{~mm}^{2}$ is more time consuming and requires higher number of samples.

Microtensile bond strength testing methodology was selected for this study, since bond strength is inversely proportional to the bonded surface area and although much higher bond strengths were measured as compared to shear test, most of the failure still occur at the interface between resin dentin inter face and are predominantly adhesive in nature ${ }^{9}$. Other advantage includes the ability to check bonding effectiveness to clinically relevant substrates such as sclerotic or carious dentin. By preparing the bonded interface with a dimension of $1 \mathrm{~mm}^{2}$, the defects in the specimen preparation such as flaws or porosities could be minimized. Though it is a labor intensive, technically demanding and relatively fragile sample preparation technique, it actually better simulates the clinical circumstances.

The present study showed that the bond strength values were higher for specimen tested in group II (with out 3\% sodium hypochlorite treatment) as compared to group I (treated with $3 \%$ sodium hypochlorite solution for 1 minute). The results are similar to other previous studies which showed that the sodium hypochlorite irrigation caused significantly lower bond strengths to dentin ${ }^{10,11}$. The lower bond strength would have resulted from damage to the organic components of dentin, there by monomer penetration into the demineralized dentin was not sufficient to create proper bond as mentioned earlier. Oxygen released by sodium hypochlorite molecules is another factor that might justify the decreased bond strength values, as it may inhibit adhesive polymerization and hence compromise the mechanical performance of the obtained bonding interfaces ${ }^{13}$. From this it can be speculated that removal of collagen fibers from dentinal surface by sodium hypochlorite might have prevented creation of a healthy hybrid layer and consequently resulted in lower bond strength values. Even though the bond strength values were reduced among the bonding agents used in combination with the sodium hypochlorite irrigation, it may not affect the clinical performance of the bonding agents tested in this study especially the agents represented in subgroup A and subgroup C. Usually bond strength value of $17-21 \mathrm{MPa}$ is desirable for adequate performance of adhesive restorative materials in terms of counter acting the polymerization stresses, transfer of functional stresses across the interface and bond durability. Although deep dentin has been regarded as a challenging bonding substrates in vital teeth because of its high wetness, such dentin can be dried in non vital teeth and can give high bond strength ${ }^{14}$. If the intention of the use of adhesive resins inside the pulp chamber is to seal the root canal to prevent microleakage of oral micro organisms and their products, then high bond strengths are not required, since the correlation between bond strength and microleakage is not high ${ }^{15}$. However if adhesive resins are to used to retain core build ups, then total etch adhesive such as Single Bond 2, represented in subgroup A, or a self- etch adhesive (AdheSE) represented in subgroup $\mathrm{C}$ would be a better choice.

In the absence of sodium hypochlorite treatment predentin would have remained on dentin surfaces, hence all the bonding agents produced clinically acceptable bond strength to such surfaces. Due to higher tubule density at the pulp chamber wall, there is little intertubular dentin between tubules to permit hybrid layer formation. Thus most of the hybrid layer in deep dentin will be made up of hybridized resin tags ${ }^{16}$. Similarly strength of resin dentin bond in the deepest dentin is probably due to both the strength of resin tags and surrounding hybridized dentin ${ }^{17}$.

Lower bond strengths obtained with Prime and Bond NT represented as sub group B may be due to the collapse of collagen fibers due to over etching because of absence of smear layer or smear plugs. This collapse of collagen would have inhibited the penetration of adhesive resin and resulted in a weak hybrid layer ${ }^{18}$. Higher bond strengths obtained with the water and ethanol based Single Bond 2 can be due the result of simultaneous inclusion of a high vapor pressure solvent ethanol and water base in the adhesive enabling the rewetting of dentin which would have resulted in collagen rehydration. This could have resulted in the formation of an adequate hybrid layer ${ }^{19-20}$. To over come the adverse effect of sodium hypochlorite on dentin substrate sodium ascorbate can be utilized before restorative procedure ${ }^{21}$.

It is obvious that bond strength values alone are not sufficient to evaluate the ability of resins to seal dentin inside the pulp chamber, indeed both microleakage and bond strength studies must be done on any adhesive system when intended to be used for restoring teeth after endodontic therapy.

From the results of the present study it can be concluded that sodium hypochlorite reduced the bond strength and water based adhesive system and self-etch system bonded better to the pulp chamber wall.

\section{REFERENCES}

1. Nakabyashi N, Pashley DH. Hybridization of dental hard tissues. 1st edn. Tokyo, Japan, Quint Publishing: 82-3

2. Gutmann JL. The dentin-root complex: anatomic and biologic considerations in restoring endodontically treated teeth. J Prosthet Dent 1992;67:458-67 http://dx.doi.org/10.1016/0022-3913(92)90073-J

3. Hennequin M, Pajot J, Avignnt D. The effects of different PH values of citric acid solutions on the calcium and phophous contents of human rot dentin. J Endodont 1994;20:551-4 http://dx.doi.org/10.1016/S00992399(06)80071-3

4. Hennequin M, Douillard Y. the effects citric acid treatment on the Ca, P and Mg contents of human dental roots. J Clin Periodontol 1995;22:5507 http://dx.doi.org/10.1111/j.1600-051X.1995.tb00804.x PMid:7560239

5. Rotstein I, Dankner E, Goldman A, Heling I, Stabholz A, ZalkindM. Histochemical analysisof dental hard tissues following bleacing.j Endod $1996 ; 22: 23-6$ 
6. SuzukiT, Finger W. Dental Adhesives; site of dentin versus bonding of composite resins. Dent Mater 1988;4:379-83 http://dx.doi.org/ 10.1016/S0109-5641(88)80053-8

7. Pashley EL, Tao L, Mathews WG, Pashley DH. Bond strength to superficial, intermediate and deep dentin in vivo with four dentin bonding systems. Dent Mater 1993;9:19-22 http://dx.doi.org/10.1016 /0109-5641(93)90099-C

8. P.N.R. Pereira, M. Okuda, H. Sano, T. Yoshikawa, M.F. Burrow, J. Tagami. Effect of intrinsic wetness and regional difference on dentin bond strength. Dent Mater 1999;15: 46-53 http://dx.doi.org/10.1016/S0109-5641(99)00013-5

9. Sano H, Shono T, Sonoda H, Takatsu T, Cicucchi B, Carvalho R et al. Relationship between surface area for adhesion and tensile bond strength- evaluation of microtensile bond strength test. Dent Mater 1994;10:236-240 http://dx.doi.org/10.1016/0109-5641(94)90067-1

10. Nikaido T, Takano Y, Sasafuchi Y, Burrow MF, Tagami J. Bond strengths to endodontically treated teeth. Am J Dent 1999;12:177-80 PMid: 10649923

11. S. Belli, Yi Zhang, P.N.R. Pereira and H. Pashley. Adhesive sealing of the pulp chamber. J Endodon 2001;27:527-32 http://dx.doi.org /10.1097/00004770-200108000-00007 PMid:11501591

12. Ninoshka GOMEZ, Alessndra REIS, Marcela ROCHA, Alessandro Dourado and Leonordo Eloy. Effect of sodium hypochlorite on the bond strength of an adhesive system to superficial and deep dentin J Appl Oral Sci 2003;11:223-8 http://dx.doi.org/10.1590/S167877572003000300012

13. Pashley DH. Clinical evaluation of dentin structure and function. Prosthet Dent 1991;66:777-81 http://dx.doi.org/10.1016/00223913(91)90414-R
14. Hilton TJ. Can modern restorative procedure really seal cavities? In vitro observations. Trans Acad Dent Mater1998;21-31

15. Pashley DH, Sano H, Yoshiyama M, Ciucchi B, Carvalho RM. Dentin a dynamic bonding substrate;the effects of dentin variables on resin adhesion. Quintessence publishing Co., 1996:11-21

16. Pashley DH, Ciucchi B, Sano H, Carvalho RM, Russel CMBond strength versus dentin structure: a modelling approach. Arch Oral Biol 1988;40:1109-18 http://dx.doi.org/10.1016/0003-9969(95)00090-9

17. Phrukkanon S, BurrowMF, Tyas MJ. The effect of dentin location and tubule orientation on the bond strengths between resin and dentin. J Dent 1999;27:265-74 http://dx.doi.org/10.1016/S0300-5712(98)00060-8

18. Tay FR, AJ Gwinnett, KM Pang, Wei SH. Resin permeation into acidconditioned moist and dry dentin: A paradigm using water free adhesive primers. J Dent Res 1996;75:1034-1044 http://dx.doi.org/10.1177/ 00220345960750040601 PMid:8708133

19. Van Meerbek B, Yoshida Y, Lambrects P et al. A TEM study of water based adhesive systems bonded to dry and wet dentin. J Dent Res 1998;77:50-59 http://dx.doi.org/10.1177/00220345980770010501

20. Romney RL, Dickens SH. Bonding to dry dentin with water modified acetone based primers, j Dent Res 1997;76:257

21. Nataya vongphan et al. Effects of sodium ascorbate on microtensile bond strength of total-etching adhesive system to $\mathrm{NaOCl}$ treated dentine. Journal of Dentistry 10/2005;33(8) 689-95

\section{Cite this article as:}

Bhat Gowrish S., Mohan B., Lakshminarayanan.L., Savadamoorthi. A comparative evaluation of effect of Sodium hypochlorite on microtensile bond strength of three different bonding agents to the lateral walls of pulp chamber: An in vitro study. Int. Res. J. Pharm. 2013; 4(3):156-159 